\title{
Factors influencing serum chemerin and kallistatin concentrations in patients with alcohol-induced liver cirrhosis
}

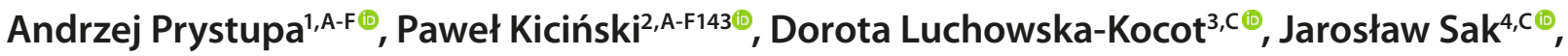 \\ Tomasz Karol Prystupa ${ }^{5, B}{ }^{\oplus}$, Yung-Hsu Tan ${ }^{6, B}{ }^{\oplus}$, Lech Panasiuk ${ }^{7, B}{ }^{\oplus}$, Wojciech Załuska ${ }^{8, B}{ }^{\oplus}$ \\ ${ }^{1}$ Department of Internal Medicine, Medical University, Lublin, Poland \\ ${ }^{2}$ Department of Experimental Haematooncology, Medical University, Lublin, Poland \\ ${ }^{3}$ Department of Medical Chemistry, Medical University, Lublin, Poland \\ ${ }^{4}$ Department of Ethics and Human Philosophy, Medical University, Lublin, Poland \\ ${ }^{5}$ Independent Public Teaching Hospital No. 4, Lublin, Poland \\ ${ }^{6}$ Students' Scientic Society, Medical University, Lublin, Poland \\ 7 Department of Internal Diseases and Hypertension, Institute of Rural Health, Lublin, Poland \\ ${ }^{8}$ Department of Nephrology, Medical University, Lublin, Poland \\ A - Research concept and design, B - Collection and/or assembly of data, C - Data analysis and interpretation, \\ $D$ - Writing the article, $E$ - Critical revision of the article, F - Final approval of article
}

Prystupa A, Kiciński P, Luchowska-Kocot D, Sak J, Prystupa TK, Tan Y-H, Panasiuk L, Załuska W. Factors influencing serum chemerin and kallistatin concentrations in patients with alcohol-induced liver cirrhosis. Ann Agric Environ Med. 2019; 26(1): 143-147. doi: 10.26444/aaem/100536

\section{Abstract}

Introduction. In Poland, an increasing number of patients are hospitalized due to liver diseases. One of the common liver diseases is cirrhosis, which can be caused by alcohol, viral hepatitis, autoimmune processes and metabolic diseases.

Materials and method. The study included 99 patients with alcoholic cirrhosis from the Lublin region of Eastern Poland. The control group consisted of 20 healthy individuals without liver disease who did not abuse alcohol. The concentrations of serum kallistatin and chemerin were determined using ELISA kits.

Objective. The aim of the study is to evaluate serum levels of kallistatin and chemerin in patients with different stages of alcoholic liver cirrhosis.

Results. The highest chemerin level was found in the control group $-182.6 \pm 80.4 \mathrm{ng} / \mathrm{ml}$. In other stages of liver cirrhosis, the following levels were observed: $175.7 \pm 62.7 \mathrm{ng} / \mathrm{ml}$ in Child-Pugh stage A (Ch-P A), 150.2 $\pm 59.7 \mathrm{ng} / \mathrm{ml}$ in Ch-P B and $110.3 \pm 73.6$ $\mathrm{ng} / \mathrm{ml}$ in Ch-PC. Significant differences in chemerin levels between controls and Ch-P C patients $(p=0.01)$, as well as between the Ch-P A patients and Ch-P C patients $(p=0.02)$, were demonstrated.

The highest kallistatin level was demonstrated in the control group $-8.2 \pm 3.5 \mu \mathrm{g} / \mathrm{ml}$. In other stages of liver cirrhosis, the following concentrations were found: $7.2 \pm 27 \mu \mathrm{g} / \mathrm{ml}$ in Ch-P A, $4.4 \pm 2.2 \mu \mathrm{g} / \mathrm{ml}$ in Ch-P B and 3.5 $\pm 1.9 \mu \mathrm{g} / \mathrm{ml}$ in Ch-P C (Tab. 3). Statistically significant differences were observed between controls and Ch-P B patients $(p<0.001)$, controls and Ch-P C patients $(p<0.001)$, Ch-P A and Ch-P B patients $(p=0.01)$, as well as Ch-P A and Ch-P C patients $(<0.001)$.

Conclusions. The levels of chemerin and kallistatin decrease with progression of liver damage during alcoholic liver cirrhosis. The impairment of its synthetic function leads to reductions in levels of the adipokines studied.

\section{Key words}

alcohol-induced liver cirrhosis, chemerin, kallistatin

\section{INTRODUCTION}

In Poland, an increasing number of patients are hospitalized due to liver diseases. One of the common liver diseases is cirrhosis, which can be caused by alcohol, viral hepatitis, autoimmune processes and metabolic diseases [1].

Alcohol induces liver cirrhosis via the harmful effects of acetaldehyde. Moreover, genetic factors, oxidative stress and impaired balance of proinflammatory, proangiogenic, and fibrogenesis-promoting cytokines are involved [2]. Recent studies also demonstrate a significant role of metabolic disorders in the progression of alcohol-induced liver cirrhosis [3]. Chemerin, discovered in 1998, is mainly synthesized in the adipose tissue as well as in the hepatic stellate cells [4]. Chemerin is a relevant element of the immune system involved in the initial stages of acute inflammation and its

Address for correspondence: Andrzej Prystupa, Medical University, Lublin, Poland e-mail: aprystup@wp.pl

Received: 03.08.2018; accepted: 06.12.2018; first published: 03.01.2019 subsidence [5]. Serum levels of chemerin have been found to correlate with inflammatory markers, such as CRP and proinflammatory cytokines (tumour necrosis factor alpha TNF- $\alpha$, interleukin 6) $[6,7]$.

Kallistatin is a protein of the serpin superfamily of serine protease inhibitors; its first described function was the inhibition of kallikrein. The protein is predominantly produced in the liver and its main physiological role is the inhibition of inflammation, fibrosis and oxidative stress [8]. Kallistatin reduces collagen fraction volume as well as deposition and expression of collagen types I and II. Moreover, it inhibits fibronectin and collagen expression by suppressing the generation of angiotensin II-induced reactive oxygen species and transforming growth factor- $\beta 1$ expression in cultured mesangial cells [9]. Kallistatin plays a role in the inhibition of tumour growth and angiogenesis by suppressing VEGF- and bFGF-induced proliferation, migration, and adhesion of endothelial cells [10].

To date, a limited number of studies on chemerin and kallistatin in liver diseases of various etiologies have been 
published, but little attention has been pain to alcoholic liver cirrhosis.

The aim of the present study was to evaluate serum levels of kallistatin and chemerin and the factors affecting them in patients with different stages of alcoholic liver cirrhosis.

\section{MATERIALS AND METHOD}

The study included 99 patients with alcoholic cirrhosis from the Lublin Region of Eastern Poland. Liver cirrhosis was diagnosed based on clinical features, history of heavy alcohol consumption, laboratory tests and abdominal ultrasonography. The patients with alcoholic hepatitis, hepatocellular carcinoma, viral and autoimmune diseases were excluded from the study. Other exclusion criteria were: type 2 diabetes, obesity, acute infections (e.g. pneumonia, spontaneous bacterial peritonitis), acute and chronic heart failure (> NYHA I), acute and chronic respiratory disorders resulting in respiratory insufficiency, acute kidney injury and chronic kidney disease (> stage G2). Both clinical assessment and laboratory tests were used to exclude the underlying liver diseases in the control group. The degree of liver cirrhosis was evaluated according to the Child-Turcotte-Pugh criteria (Child-Pugh score) [11] ${ }^{1}$. Based on the above, patients were assigned to one of three groups: Child-Pugh (Ch-P) A - 29 with stage A, Ch-P B - 26 with stage B and Ch-P C - 34 with stage $\mathrm{C}$ of liver cirrhosis. The control group consisted of 20 healthy individuals without liver disease who did not abuse alcohol. There were no significant age- or gender-related differences in the groups (Tab. 1). Detailed demographic, clinical and biochemical characteristics of patients are presented in Table 1 and 2. The study protocol was approved by the Ethics Committee. All subjects gave their written informed consent for participation in the study.

Determination of serum chemerin concentration. Serum chemerin concentration was determined using Biovendor Human Chemerin ELISA kit (BioVendor, Czech Republic). In this assay, standards, quality controls and 100-fold diluted samples were incubated in microtitration wells pre-coated with polyclonal anti-human chemerin antibody. After a 60-minute incubation followed by washing, biotin labelled polyclonal anti-human chemerin antibody was added and incubated with the captured chemerin for 60 minutes. After another washing, streptavidin-HRP conjugate was added. After another incubation, the remaining conjugate was allowed to react with the substrate solution (TMB). The reaction was stopped by addition of acidic solution and absorbance of the products was measured using the Epoch Microplate Spectrophotometer, USA $(\lambda=450 \mathrm{~nm})$. The results were multiplied by dilution factor (100).

Determination of serum kallistatin concentration. Serum kallistatin concentration was determined applying Human kallistatin ELISA sandwich enzyme immunoassay (BioVendor, Czech Republic). In this assay, standards and samples (5,000-fold diluted serum) were incubated in microtitrate pre-coated with polyclonal anti-human kallistatin antibody. After incubation, biotin labelled antibody was added. Further procedure (addition of streptavidin-HRP conjugate, substrate and stop solution etc.) was analogous to the assay described above. Absorbance of standards and samples was measured spectrophotometrically at a wavelength of $450 \mathrm{~nm}$. The concentration of kallistatin was determined using the standard curve constructed for standards. The results were multiplied by a dilution factor $(5,000)$.

Statistical analysis. STATISTICA 13 (Statsoft, Inc.) was used for data analysis. Continuous variables were expressed as the mean \pm standard deviation (SD). Before calculations, variables were checked for normality using the Shapiro-Wilk test; the Brown-Forsythe's test was applied to test equality of variances. To compare the results between more than two groups, one-way ANOVA test was used. The Tukey`s test was applied for detailed identification of statistically different groups. Correlations among variables were performed using the Pearson's correlation test. Stepwise multiple linear regression analysis was applied to determine the potential independent influence of various factors on chemerin and kallistatin concentrations. Qualitative variables are shown as indicators of structure (percentage); for intergroup comparisons, the $\chi^{2}$ test was used. Receiver operating characteristic (ROC) curves were used to assess diagnostic accuracy of chemerin and kallistatin. For all tests, $\mathrm{p}<0.05$ was considered as statistically significant.

\section{RESULTS}

Demographic and clinical characteristics of the control and alcoholic liver cirrhosis group are presented in tables 1 and 2 .

Table 1. Demographic and clinical characteristics of study and control groups

\begin{tabular}{lcccc}
\hline & \multirow{2}{*}{$\begin{array}{c}\text { Control group } \\
(\mathrm{n}=20)\end{array}$} & \multicolumn{3}{l}{ Alcoholic liver cirrhosis $(\mathrm{n}=99)$} \\
\cline { 3 - 5 } & $48.9 \pm 15.1$ & $53.3 \pm 12.3$ & $54.6 \pm 11.0$ & $56.9 \pm 7.7$ \\
\hline $\mathrm{n}=29)$ & $\begin{array}{c}\text { Ch-P B } \\
(\mathrm{n}=36)\end{array}$ & $\begin{array}{c}\mathrm{Ch}-\mathrm{PC} \\
(\mathrm{n}=34)\end{array}$ \\
\hline Age (years) & $65 \%$ & $72.4 \%$ & $66.7 \%$ & $58.8 \%$ \\
\hline percentage of men & $170.4 \pm 6.6$ & $171.8 \pm 7.8$ & $175.3 \pm 8.4$ & $173.4 \pm 6.9$ \\
\hline Height (cm) & $67.8 \pm 7.8$ & $68.1 \pm 14.8$ & $71.5 \pm 13.2$ & $70.2 \pm 12.8$ \\
\hline Body mass (kg) & - & $13.1 \pm 4.8$ & $14.1 \pm 4.9$ & $15.7 \pm 5.4$ \\
\hline Time of alcohol abuse (years) & 0 & $32 \%$ & $61 \%$ & $85 \%$ \\
\hline Ascites (\%) & 0 & $14 \%$ & $45 \%$ & $88 \%$ \\
\hline Oesophageal varices (\%) & 0 & $28 \%$ & $51 \%$ & $91 \%$ \\
\hline Encephalopathy (\%) & & & &
\end{tabular}

The study findings demonstrated that the serum chemerin level decreased depending on the stage of liver cirrhosis (Fig.1). The highest chemerin level was found in the control group $-182.6 \pm 80.4 \mathrm{ng} / \mathrm{ml}$. In other stages of liver cirrhosis, the following levels were observed: $175.7 \pm 62.7 \mathrm{ng} / \mathrm{ml}$ in Ch-P A, $150.2 \pm 59.7 \mathrm{ng} / \mathrm{ml}$ in Ch-P B and $110.3 \pm 73.6 \mathrm{ng} / \mathrm{ml}$ in Ch-P $\mathrm{C}$ (Tab. 3). Analysis of variance (ANOVA) and the Tukey's test disclosed significant differences in chemerin levels between controls and Ch-P C patients ( $\mathrm{p}=0.01)$, as well as between the Ch-P A patients and Ch-P C patients $(\mathrm{p}=0.02)$.

Likewise, the serum level of kallistatin decreased in decompensated liver cirrhosis (Fig. 2). The highest kallistatin level was demonstrated in the control group $-8.2 \pm 3.5 \mu \mathrm{g} / \mathrm{ml}$. In other stages of liver cirrhosis, the following concentrations were found: $7.2 \pm 27 \mu \mathrm{g} / \mathrm{ml}$ in Ch-P A, $4.4 \pm 2.2 \mu \mathrm{g} / \mathrm{ml}$ in Ch-P B 
Table 2. Biochemical characteristics of study and control groups

\begin{tabular}{|c|c|c|c|c|}
\hline & \multirow{2}{*}{$\begin{array}{l}\text { Control group } \\
\qquad(n=20)\end{array}$} & \multicolumn{3}{|c|}{ Alcoholic liver cirrhosis $(n=99)$} \\
\hline & & $\begin{array}{l}\text { Ch-P A } \\
(n=29)\end{array}$ & $\begin{array}{l}\text { Ch-P B } \\
(n=36)\end{array}$ & $\begin{array}{l}\text { Ch-P C } \\
(n=34)\end{array}$ \\
\hline Bilirubin (mg/dl) & $0.68 \pm 0.28$ & $2.21 \pm 1.4$ & $4.12 \pm 3.25$ & $7.89 \pm 7.94$ \\
\hline Albumin (g/dl) & - & $3.27 \pm 0.76$ & $2.78 \pm 0.6$ & $2.44 \pm 0.46$ \\
\hline $\begin{array}{l}\text { International } \\
\text { normalized ratio } \\
\text { (INR) }\end{array}$ & - & $1.25 \pm 0.27$ & $1.44 \pm 0.29$ & $1.68 \pm 0.41$ \\
\hline Platelets (G/I) & $226.8 \pm 35.8$ & $186.03 \pm 76.9$ & $123.6 \pm 66.25$ & $114.11 \pm 61.6$ \\
\hline $\begin{array}{l}\text { Mean cell volume } \\
(\mathrm{MCV})(\mathrm{fl})\end{array}$ & $94.65 \pm 4.45$ & $92.38 \pm 6.25$ & $91.9 \pm 10.08$ & $97.53 \pm 8.02$ \\
\hline Urea (mg/dl) & - & $32.04 \pm 20.1$ & $23.49 \pm 15.62$ & $39.58 \pm 16.1$ \\
\hline Sodium (mmol/l) & $139.82 \pm 3.24$ & $133.67 \pm 5.3$ & $135.38 \pm 3.6$ & $133.51 \pm 6.63$ \\
\hline Potassium (mmol/l) & $4.41 \pm 0.37$ & $3.88 \pm 0.6$ & $3.94 \pm 0.6$ & $3.3 \pm 0.66$ \\
\hline $\begin{array}{l}\text { C-reactive protein, } \\
\text { CRP }(\mathrm{mg} / \mathrm{l})\end{array}$ & $2.11 \pm 1.96$ & $14.97 \pm 12.62$ & $19.21 \pm 17.35$ & $20.8 \pm 19.92$ \\
\hline $\begin{array}{l}\text { Aspartate } \\
\text { transaminase (ASP) } \\
(\mathrm{U} / \mathrm{l})\end{array}$ & $18.1 \pm 5.2$ & $53.1 \pm 21.8$ & $145.5 \pm 110.7$ & $188.3 \pm 107.4$ \\
\hline
\end{tabular}

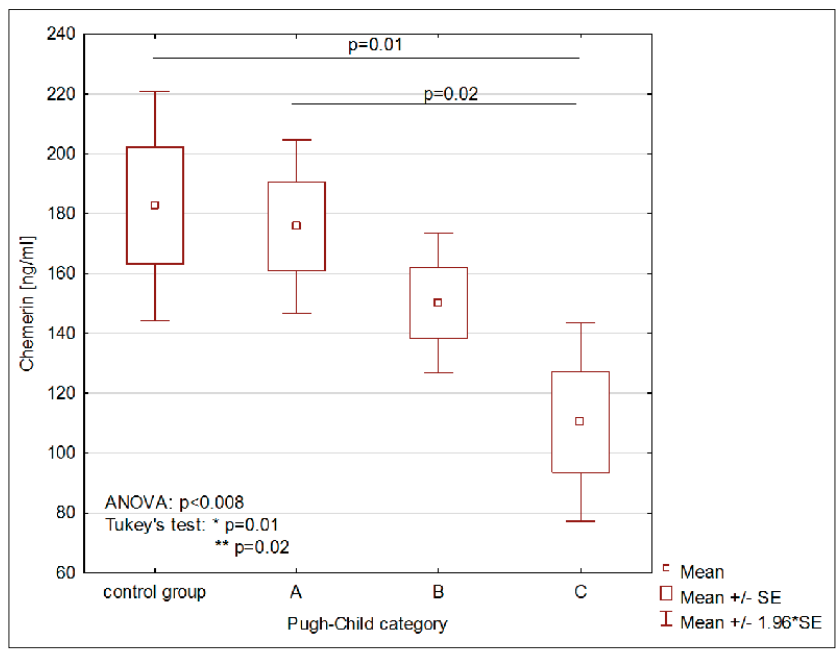

Figure 1. Chemerin levels in patients with alcoholic liver cirrhosis and in the control group

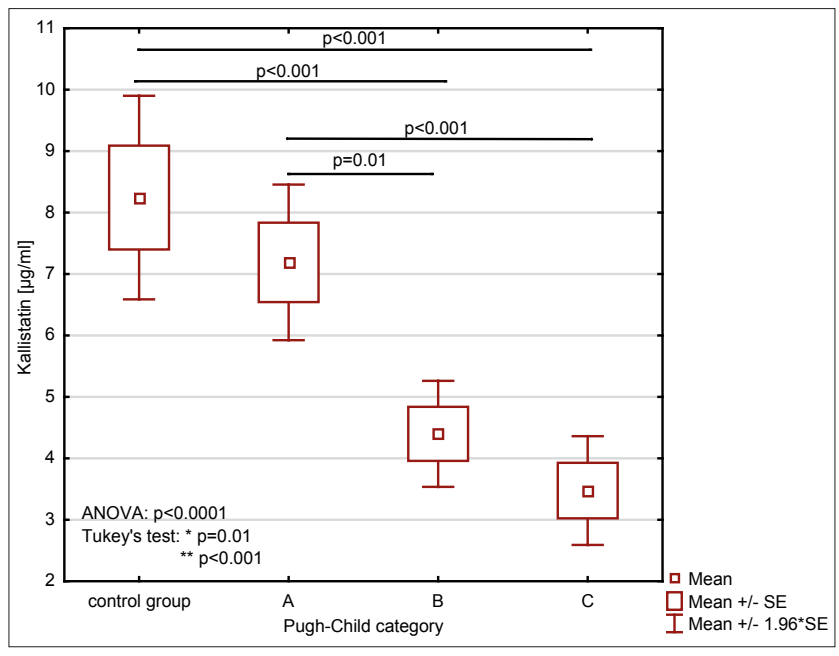

Figure 2. Kallistatin levels in patients with alcoholic liver cirrhosis and in controls and 3.5 $\pm 1.9 \mu \mathrm{g} / \mathrm{ml}$ in Ch-P C (Tab. 3). Statistically significant differences were observed between controls and Ch-P B patients $(\mathrm{p}<0.001)$, controls and Ch-P C patients $(\mathrm{p}<0.001)$, Ch-P A and Ch-P B patients $(\mathrm{p}=0.01)$, as well as Ch-P A and Ch-P C patients $(<0.001)$.

Table 3. Levels of chemerin and kallistatin in patients with alcoholic liver cirrhosis and in the control group

\begin{tabular}{lcccc}
\hline \multirow{2}{*}{ Controls } & \multicolumn{3}{c}{ Alcoholic liver cirrhosis } \\
\cline { 3 - 5 } & & Ch-P A & Ch-P B & Ch-P C \\
\hline Chemerin $[\mathrm{ng} / \mathrm{ml}]$ & $182.6 \pm 80.4$ & $175.7 \pm 62.7$ & $150.2 \pm 59.7$ & $110.3 \pm 73.6$ \\
\hline Kallistatin $[\mu \mathrm{g} / \mathrm{ml}]$ & $8.2 \pm 3.5$ & $7.2 \pm 2.7$ & $4.4 \pm 2.2$ & $3.5 \pm 1.9$
\end{tabular}

Correlations between serum levels of chemerin and kallistatin versus selected clinical and laboratory parameters were also analyzed (Tab. 4). Negative correlations were found between serum chemerin versus the level of bilirubin $(\mathrm{r}=-0.48$; $\mathrm{p}<0.001)$, INR $(\mathrm{r}=-0.56 ; \mathrm{p}<0.001)$ and mean cell volume $(\mathrm{r}=-$ $0.36 ; \mathrm{p}=0.004)$. Positive correlations were observed between chemerin versus albumin concentration $(\mathrm{r}=0.45 ; \mathrm{p}=0.003)$ and platelet count $(\mathrm{r}=0.37 ; \mathrm{p}=0.003)$. In the case of kallistatin, the only correlations noted were with the concentration of bilirubin $(r=-0.26 ; p=0.045)$ and albumin $(r=0.45 ; p=0.003)$.

Table 4. Correlations between levels of chemerin and kallistatin versus laboratory parameters

\begin{tabular}{lcc}
\hline & \multicolumn{1}{c}{ Chemerin } & Kallistatin \\
\hline Total bilirubin & $r=-0.48 ; p<0.001$ & $r=-0.26 ; p=0.045$ \\
\hline Albumin & $r=0.45 ; p=0.003$ & $r=0.45 ; p=0.003$ \\
\hline PLT & $r=0.37 ; p=0.003$ & $N S$ \\
\hline MCV & $r=-0.36 ; p=0.004$ & $N S$ \\
\hline INR & $r=-0.56 ; p<0.001$ & $r=-0.47 ; p<0.001$ \\
\hline ASP & NS & $r=-0.27 ; p=0.03$ \\
\hline CRP & NS & $N S$
\end{tabular}

To assess an independent association between other variables and levels of chemerin and kallistatin, multiple regression analysis was used. An independent correlation was found between chemerin versus concentration of bilirubin, albumin and platelet count. The above model explains 52\% of chemerin variance, which was most strongly affected by the level of bilirubin $\left(b^{*}=-0.42\right)$.

Table 5. Independent variables associated with the level of chemerin multiple linear regression

\begin{tabular}{lccccc}
\hline Independent variables & $\mathrm{b}^{*}$ & $\mathrm{SE}$ & $\mathrm{b}$ & $\mathrm{SE}$ & $\mathrm{p}$ \\
\hline Total bilirubin & -0.42 & 0.11 & -4.37 & 1.14 & $<0.001$ \\
\hline Albumin & 0.36 & 0.11 & 39.1 & 11.7 & $<0.01$ \\
\hline PLT & 0.36 & 0.11 & 0.35 & 0.1 & $<0.01$ \\
\hline
\end{tabular}

Model: $\mathrm{R}^{2}=0.56$, adjusted $\mathrm{R}^{2}=0.52, \mathrm{p}<0.0001$.

$\mathrm{b}^{*}$ - standardized coefficient of regression; $\mathrm{b}$ - coefficient of regression; SE - standard error; $\mathrm{R}^{2}$ - coefficient of determination.

Furthermore, the multiple regression model for kallistatin included only two independent variables - INR $\left(b^{*}=-0.41\right)$ and ascites $\left(b^{\star}=-0.31\right)$. It is noteworthy that this model was more poorly adjusted to the empirical data as the adjusted coefficient of determination was 0.28 . Nevertheless, this was the optimal model to design. 
Table 6. Independent variables associated with the level of kallistatin multiple linear regression

\begin{tabular}{lccccc}
\hline Independent variables & $\mathrm{b}^{*}$ & $\mathrm{SE}$ & $\mathrm{b}$ & $\mathrm{SE}$ & $\mathrm{p}$ \\
\hline Intercept & & & 11.3 & 1.5 & $<0.0001$ \\
\hline INR & -0.41 & 0.13 & -2.8 & 0.9 & $<0.01$ \\
\hline Ascites & -0.31 & 0.13 & -2.1 & 0.9 & 0.02 \\
\hline Model: $\mathrm{R}^{2}=0.31$; adjusted $\mathrm{R}^{2}=0.28 ; \mathrm{p}<0.001$. & & &
\end{tabular}

Model: $R^{2}=0.31 ;$ adjusted $R^{2}=0.28 ; p<0.001$

$b^{*}$ - standardized coefficient of regression; b - coefficient of regression;

$\mathrm{SE}$ - standard error; $\mathrm{R}^{2}$ - coefficient of determination.

To assess the usefulness of chemerin and kallistatin as markers of alcoholic liver cirrhosis, analysis of receiveroperator characteristic (ROC) curves was performed (Fig. 3). The area under the curve (AUC) was 0.653 at $95 \%$ confidence interval:0.5-0.81 $(\mathrm{p}=0.51)$ and 0.782 at $95 \%$ CI $0.66-0.9$ $(\mathrm{p}<0.0001)$ for chemerin and kallistatin, respectively.

At the cut-off point of $159 \mathrm{ng} / \mathrm{ml}$, the sensitivity of chemerin for detecting liver cirrhosis was $64 \%$ and the specificity $69 \%$. At the cut-off point of $5.61 \mu \mathrm{g} / \mathrm{ml}$, the sensitivity of kallistatin was $64 \%$ and the specificity $77 \%$.

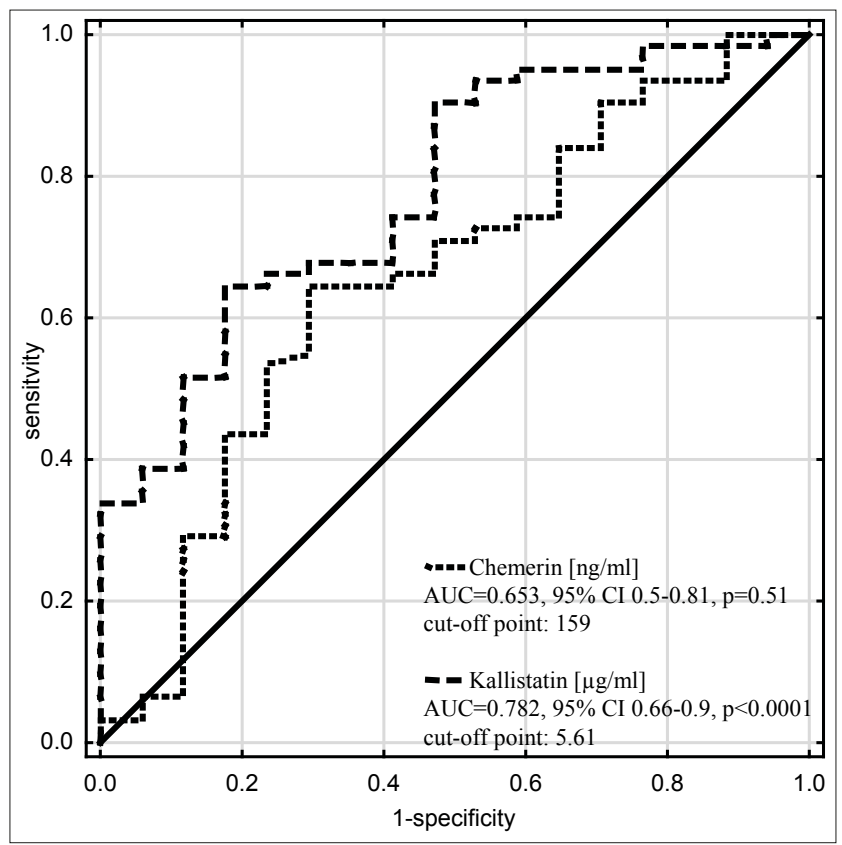

Figure 3. Comparison of $\mathrm{ROC}$ curves for chemerin and kallistatin

\section{DISCUSSION}

The presented findings demonstrate decreased chemerin levels in the alcoholic cirrhosis group, depending in the stage of disease. The highest chemerin level was found in the control group $(182.6 \pm 80.4 \mathrm{ng} / \mathrm{ml})$, whereas the lowest in Ch-P C group (110.3 $\pm 73.6 \mathrm{ng} / \mathrm{ml})$.

Under physiological conditions, chemerin is produced in the adipose tissue, liver and placenta [12]. Chemerin is a factor modulating the inflammatory process [13] and its serum levels are induced in inflammatory diseases [14]. Additionally, increased serum levels of chemerin in patients with liver failure can result from reduced glomerular filtration and impaired chemerin excretion with urine [15]. Furthermore, increased levels of chemerin are observed in chronic hepatitis C [16]. According to Kukla et al., chemerin is increased in patients with liver steatosis and non-alcoholic steatohepatitis (NASH) [17].

Chemerin serum levels also decrease with the development of fibrosis and liver cirrhosis. Gradual impairment of the liver synthetic function leads to reduced synthesis of chemerin. In individuals with liver cirrhosis, the adipose tissue atrophies, which is likely to additionally reduce the production of chemerin. Imai et al. have demonstrated that levels of chemerin in patients with liver cirrhosis complicated by HCC were inversely correlated with Child-Pugh scores [18]. Moreover, the results of the current study have shown that serum chemerin levels were significantly correlated with platelet counts. Eisinger et al. found that chemerin levels were significantly lower in patients with Ch-P score $\mathrm{C}$ compared to A. Moreover, chemerin levels were lower in patients with Child-Pugh score $\mathrm{C}$ compared to B. Chemerin mRNA levels in the cirrhotic livers negatively correlated with serum bilirubin but not with prothrombin over time.

However, chemerin did not correlate with C-reactive protein, albumin, ALT, AST, alkaline phosphatase, bilirubin or fibrinogen in the cirrhotic patients [14]. In the current study, there was also no correlation between kallistatin levels and CRP. The only relevant factors associated with serum chemerin levels were albumin and platelet count.

The next cytokine studied was kallistatin. The findings of the current study revealed that the levels of kallistatin in patients with alcoholic liver cirrhosis were statistically significantly lower compared to controls. Moreover, the level of kallistatin decreased with the stage of alcoholic liver cirrhosis. The lowest kallistatin level was found in Ch-P stage C. Similar results were reported by Cheng et al., who demonstrated that kallistatin can be a diagnostic indicator of hepatic status, especially for liver cirrhosis. A decrease in serum kallistatin levels appeared to reflect the extent of liver cirrhosis [8]. It is worth stressing that ROC analysis performed in the current study showed a relatively low sensitivity and specificity of kallistatin as an indicator of liver cirrhosis (64\% and 77\%, respectively). Thus, it seems that kallistatin as a single biomarker will not be used in routine clinical practice. Furthermore, the results obtained in this study disclosed that the factors associated with reduced serum levels of kallistatin were INR and ascites.

Kallistatin is a tissue kallikrein inhibitor [19] and has various effects, such as antioxidative, antiangiogenic, antiinflammatory, antioxidant and antiapoptotic [20]. Kallistatin is produced mostly in the liver [21] and is a negative acute phase protein, the concentration of which decreases during inflammatory processes (e.g. significantly reduced kallistatin levels were seen in the plasma of a patient with sepsis) $[19$, 22]. In cases of cirrhosis-associated liver damage, its serum levels decrease. Reduced production of kallistatin results from liver damage, especially impaired synthetic function, and correlates with the stage of liver cirrhosis.

\section{CONCLUSIONS}

The liver is the main organ that produces chemerin and kallistatin and the findings of this study demonstrate that their levels decrease with the progression of liver damage during alcoholic liver cirrhosis. The impairment of its synthetic function leads to reductions in levels of the 
adipokines studied. Additionally, reduced levels of chemerin can be affected by its diminished production by the adipose tissue, which is less metabolically active in liver cirrhosis.

\section{REFERENCES}

1. Bosetti C, Levi F, Lucchini F, Zatonski WA, Negri E, La Vecchia C. Worldwide mortality from cirrhosis: an update to 2002. J Hepatol. 2007; 46: 827-839.

2. Bruha R, Dvorak K, Petrtyl J. Alcoholic liver disease. World J Hepatol. 2012; 4(3): 81-90.

3. Ishii H, Horie Y, Yamagshi Y, Ebinuma H. Alcoholic Liver Disease and Its Relationship with Metabolic Syndrome. JMAJ. 2010; 53(4): 236-242.

4. Krautbauer S, Wanninger J, Eisinger K, Hader Y, Beck M, Kopp A, Schmid A, Weiss TS, Dorn C, Buechler C. Chemerin is highly expressed in hepatocytes and is induced in non-alcoholic steatohepatitis liver. Exp Mol Pathol. 2013; 95(2): 199-205.

5. Strojek M. Chemeryna - rola w patologii człowieka. Postepy Hig Med Dosw (online), 2017; 71: 110-117.

6. Lehrke M, Becker A, Greif M, Stark R, Laubender RP, von Ziegler F, Lebherz C, Tittus J, Reiser M, Becker C, Göke B, Leber AW, Parhofer KG, Broedl UC. Chemerin is associated with markers of inflammation and components of the metabolic syndrome but does not predict coronary atherosclerosis. Eur J Endocrinol. 2009; 161: 339-344.

7. Weigert J, Neumeier M, Wanninger J, Filarsky M, Bauer S, Wiest R, Farkas S, Scherer MN, Schäffler A, Aslanidis C, Schölmerich J, Buechler C. Systemic chemerin is related to inflammation rather than obesity in type 2 diabetes. Clin Endocrinol. 2010; 72: 342-348.

8. Cheng Z, Lv Y, Pang S, Bai R, Wang M, Lin S, Xu T, Spalding D, Habib $\mathrm{N}, \mathrm{Xu} \mathrm{R}$. Kallistatin, a new and reliable biomarker for the diagnosis of liver cirrhosis. Acta Pharm Sin B. 2015; 5(3): 194-200.

9. Shen B, Hagiwara M, Yao YY, Chao L, Chao JL. Salutary effect of kallistatin in salt-induced renal injury, inflammation, and fibrosis via antioxidative stress. Hypertension. 2008; 51: 1358-1365.

10. Miao RQ, Agata J, Chao L, Chao J. Kallistatin is a new inhibitor of angiogenesis and tumor growth. Blood. 2002; 100: 3245-3325.

11. Pugh R, Murray-Lyon I, Dawson JL, Pietroni MC, Williams R. Transection of the oesophagus for bleeding oesophageal varices. $\mathrm{Br} \mathrm{J}$ Surg. 1973, 60(8): 646-649.
12. Goralski KB, McCarthy TC, Hanniman EA, Zabel BA, Butcher EC, Parlee SD, Muruganandan S, Sinal CJ. Chemerin, a novel adipokine that regulates adipogenesis and adipocyte metabolism. J Biol Chem. 2007; 282(38): 28175-28188.

13. Zabel BA, Allen SJ, Kulig P, Allen JA, Cichy J, Handel TM, Butcher EC. Chemerin Activation by Serine Proteases of the Coagulation, Fibrinolytic, and Inflammatory Cascades. J Biol Chem. 2005; 280: 34661-34666

14. Eisinger K, Krautbauer S, Wiest R, Weiss TS, Buechler C. Reduced serum chemerin in patients with more severe liver cirrhosis. Exp Mol Pathol. 2015; 98(2): 208-213.

15. Błaszak J, Szołkiewicz M, Sucajtys E, Konarzewski M, Świerczyński J, Rutkowski B. High serum chemerin concentration in patient with chronic renal failure. Nephrol Dial Pol. 2013, 17, 49-52.

16. Kukla, M, Zwirska-Korczala K, Gabriel A, Waluga M, Warakomska I, Szczygiel B, Berdowska A, Mazur W, Wozniak-Grygiel E, Kryczka W. Chemerin, vaspin and insulin resistance in chronic hepatitis C. J Viral Hepat. 2010; 17(9): 661-667.

17. Kukla M, Zwirska-Korczala K, Hartleb M, Waluga M, Chwist A, Kajor M, Ciupinska-Kajor M, Berdowska A, Wozniak-Grygiel E, Buldak R. Serum chemerin and vaspin in non-alcoholic fatty liver disease. Scand J Gastroenterol. 2010; 45(2): 235-42.

18. Imai K, Takai K, Hanai T, Shiraki M, Suzuki Y, Hayashi H, Naiki T, Nishigaki Y, Tomita E, Shimizu M, Moriwaki H. Impact of serum chemerin levels on liver functional reserves and platelet counts in patients with hepatocellular carcinoma. Int J Mol Sci. 2014; 15(7): 11294-11306.

19. Chao J, Schmaier A, Chen LM, Yang Z, Chao L. Kallistatin, a novel human tissue kallikrein inhibitor: levels in body fluids, blood cells, and tissues in health and disease. J Lab Clin Med. 1996; 127: 612-620.

20. Chao J, Chao L. Biochemistry, regulation and potential function of kallistatin. Biol Chem Hoppe-Seyler. 1995; 376: 705-713.

21. Cheng Z, Lv Y, Pang S, Bai R, Wang M, Lin S, Xu T, Spalding D, Habib $\mathrm{N}, \mathrm{Xu}$ R. Kallistatin, a new and reliable biomarker for the diagnosis of liver cirrhosis. Acta Pharm Sin B. 2015; 5 (3): 194-200.

22. Chao J, Chen LM, Chai KX, Chao L. Expression of kallikrein-bonding protein and a1-antitrypsin genes in response to sex hormones, growth, inflammation and hypertension. Agents Actions Suppl. 1992; 38: 174181. 